\title{
The Embryo-sac of Pandanus.
}

\author{
BY
}

\section{DOUGLAS HOUGHTON CAMPBELL, Professor of Botany in Stanford University.}

\section{With Plates LIX and LX and two Figures in the Text.}

$I^{1}$

$\mathrm{T}$ is evident that the number of Angiosperms in which the embryo-sac shows more or less marked departures from the usual eight-nucleate type is larger than has been supposed. The results of recent investigations are sufficiently striking to warrant the hope that forms may yet be discovered which will throw more light upon the homologies of the structures in the embryo-sac of the Angiosperms, and their relation to the corresponding structures in the Gymnosperms and heterosporous Pteridophytes.

In selecting forms for investigation one naturally chooses those genera which for other reasons are supposed to be primitive types. Among the Monocotyledons the Pandanaceae have been placed low down in the series, and it seemed not unlikely that Pandanus might be a satisfactory subject for study; and such has proved to be the case, as it shows the least reduced type of female gametophyte that has yet been discovered among the Angiosperms.

The Pandanaceae include the genera Pandamus and Freycinetia. They are confined to the Old World, being especially abundant in the Malayan region, where they constitute a conspicuous feature of the flora. One species of each occurs in Hawaii.

During a visit to the East Indies in I906 a large amount of material was collected, mostly in Java. There is a very extensive collection of Pandanaceae at Buitenzorg, and during my stay there from March to June repeated collections were made. When this material was examined, however, it was found to be too young to show the completed structures of the embryo-sac. An account of the development of the embryo-sac, as far as it could be followed in this material, has already been published, ${ }^{2}$ but the study of the further details had to be postponed until older material could be procured.

The oldest stages secured from the Javanese material showed fourteen or sixteen nuclei in the embryo-sac, instead of the eight typical of most

1 Pandanaceae. Engleru Prantl, Natürliche Pflanzenfamilien, Part II.

2 The Embryo-sac of Pandanus. Bulletin of the Torrey Botanical Club, xxxvi, I909, pp. 205-20.

[Annals of Botany, Vol. XXV. No. XCIX. July, I911.] 
Angiosperms. Of these nuclei two were at the upper end of the sac, the others at the antipodal end. It was impossible to tell whether this stage represented the condition at the time of fertilization, and an effort was made to obtain material which would settle this question.

Through the kindness of Dr. W. R. Shaw, of Manila, formerly instructor at Stanford University, a supply of carefully preserved material was secured, which furnished the later stages of development. Dr. Shaw writes that the Philippine species is probably $P$. coronatus, Martelli, a name supposed to be synonymous with $P$. tectorius, Soland.

A study of the more advanced stages of $P$. coronatus showed that the older stages found in the Javanese species were very far from mature. A brief account of the embryo-sac of $P$. coronatus was published, but the details were reserved for further study. ${ }^{1}$

A summary of the results published in the earlier papers is given here, and in addition the history of the embryo-sac from the latest stages secured in the Javanese species to the condition of the mature embryo-sac shown in $P$.coronatus. The post-fertilization stages have also been carefully followed, including the endosperm formation and the early history of the embryo.

The species collected in Java included two small ones, $P$. Artocarpus, Griff, and $P$. affinis, Kurz, and the larger widespread species, $P$.odoratissimus, L.f., which reaches to Hawaii. Of these $P$. Artocarpus furnished the greater part of the material that was studied.

All of the Pandanaceae are dioecious. The pistillate flowers in Pandanus are in dense heads, which in the smaller species are borne several together at the end of a short branch, each head subtended by a conspicuous bract. In the larger species the inflorescence is usually solitary and enveloped in a large number of bracts. The head of fruit may occasionally be nearly or quite a foot in diameter.

The Pandanaceae have been placed close to the Sparganiaceae, the flowers as well as the spiky heads of fruit, especially in the smaller species, closely resembling those of Sparganium. In the smaller ones like P. Artocarpus and $P$. affinis, the individual flower consists of a single carpel, which closely resembles that of Sparganium simplex, except for the absence of the conspicuous scale-like bracts that are found in the latter. In the larger species several carpels are more or less completely coherent and may be compared to the compound pistils of Sparganium eurycarpum. The carpels in $P$. Artocarpus and P. affinis (Pl. LIX, Fig. I) are slender and much crowded together into nearly globular heads. The sessile stigma is elongated and sharply pointed, extending down the inner face of the carpel for about onethird of its length. In $P$. coronatus and the other species with large syncarpous fruits, the stigmas are discoid.

Each carpel contains a solitary anatropous ovule attached to one side 1 Bulletin of the Torrey Botanical Club, xxxvii, 1910, 293-5. 
of the ovarian cavity near its base. The placenta and the base of the funiculus bear closely placed glandular hairs (Text-fig. I, C, D). These hairs are probably concerned with the conduction of the pollen-tube to the micropyle. On the inner side of the ovule the outer integument is completely fused with the funiculus.

\section{The Ovule.}

The youngest ovules that were secured were from $P$. affinis. Textfig. I, A, shows a median section through the base of a young carpel of this
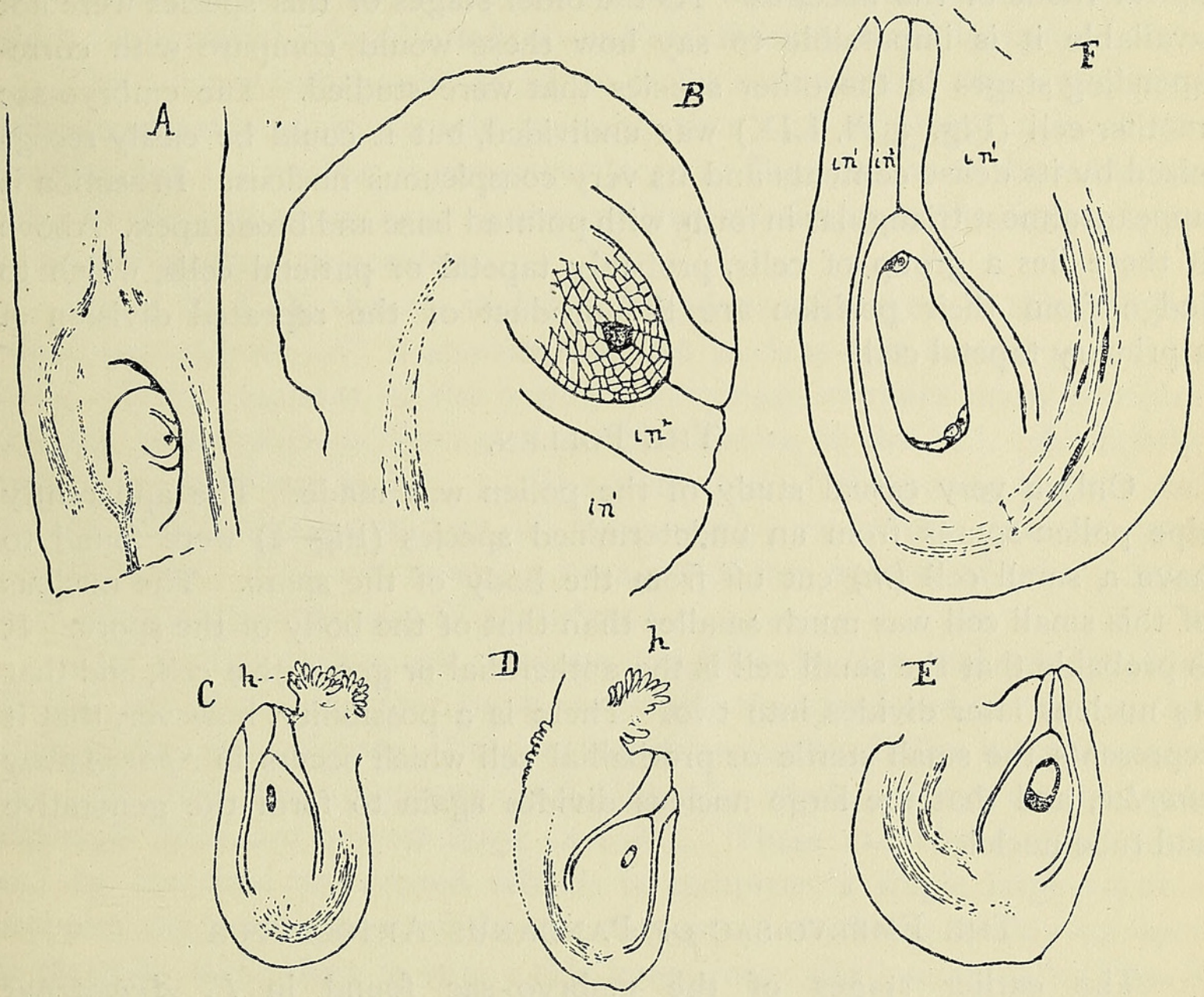

TEXT-FIG. 1. A. Section through the base of a young carpel of Pandanus affinis, Kurz, showing the single anatropous ovule. $x$ about 35 . B. The ovule more highly magnified. The sporogenous cell is shaded. $\times 235 . \quad$ in $^{1}, i n^{2}$, the integuments. C-E. Older ovules of P. Artocarpus, Griff., showing the young embryo-sac. The embryo-sac shown in E contained fourteen nuclei. $\times$ about $35 ; h$, secretory hairs upon the funiculus. F. An ovile of $P$. coronatus about ready for fertilization. $x$ about 35 . There were two 'polar' nuclei in process of fusion.

species. The ovule almost completely fills the ovarian cavity, and at this stage is a good deal flattened and the integuments do not extend much beyond the apex of the nucellus. The ovule is shown more enlarged at $\mathrm{B}$.

Text-figs. I, C, D, represent similar sections of older ovules of $P$. Artocarpus. In these older stages the nucellus becomes more elongated and the terminal portion of the integuments also becomes lengthened. 
As the ovule develops there is relatively little increase in the size of the nucellus, which becomes replaced by the enlarging embryo-sac, but the funiculus and the part of the outer integument adjoining it become much enlarged, so that the ovule has quite a different form from the earlier stages. This recalls the ovules of many Araceae, where there is a similar enlargement of the basal region of the ovule. Traversing the funiculus there is a single fibro-vascular bundle.

$P$. affinis differs slightly from the other species examined in the form of the embryo-sac mother-cell, as well as in the greater thickness of the apical tissue of the nucellus. As the older stages of this species were not available it is impossible to say how these would compare with corresponding stages in the other species that were studied. The embryo-sac mother-cell (Fig. 3, P1. LIX) was undivided, but it could be easily recognized by its dense contents and its very conspicuous nucleus. In section it appears almost triangular in form, with pointed base and broad apex. Above it there lies a group of cells, probably tapetal or parietal cells, which to judge from their position are the product of the repeated division of a primary tapetal cell.

\section{The Pollen.}

Only a very casual study of the pollen was made. The apparently ripe pollen-spores from an undetermined species (Fig. 2) were found to have a small cell $(m)$ cut off from the body of the spore. The nucleus of this small cell was much smaller than that of the body of the spore. It is probable that the small cell is the antheridial or generative cell, and that its nucleus later divides into two. There is a possibility, however, that it represents the small sterile or prothallial cell which occurs in Sparganium simplex, and that the large nucleus divides again to form the generative and tube nuclei.

\section{The Embryo-sac of Pandanus Artocarpus.}

The earlier stages of the embryo-sac found in $P$. Artocarpus (Figs. 4-6) were somewhat more advanced than that described in P.affinis. The mother-cell is more nearly cylindrical and the base is truncate, and sometimes almost as broad as the apex, and in such cases it is the lowermost of a single series of cells, or at least such is the appearance in longitudinal section (Fig. 6). More commonly the upper end of the mother-cell is rather broader, and there are two series of parietal cells to be seen in longitudinal section (Fig. 5). There are two other layers of these parietal cells between the young embryo-sac and the epidermis at the apex of the nucellus. The sporogenous cell divides transversely into two, one of which, the lower, is the larger and becomes the embryo-sac (e.s.). The upper cell $(x)$ divides into two by a vertical wall, and these two small cells persist with 
little change for some time, but they finally disintegrate and are visible only as two small, darkly stained, shrunken bodies lying above the apex of the embryo-sac. In these early stages Pandanus closely resembles the ordinary Angiosperms, except for the vertical division in the upper sporogenous cell. It differs from Peperomia and Gunnera, which in some respects resemble it more nearly than any other Angiosperms, in the formation of three cells which may be interpreted as megaspores, instead of having the primary sporogenous cell develop directly into the embryo-sac.

At what stage the reduction divisions in the nuclei occur could not be determined, since for some reason, perhaps owing to the time of day at which the material was collected, no nuclear divisions could be found.

The young embryo-sac (e.s.) is easily recognizable, the cytoplasm being noticeably more densely granular than the adjoining cells of the nucellus, and the nucleus is somewhat larger. The position of the nucleolus lying in the cytoplasm next to the nucleus, as shown in the figure, is no doubt the result of an accident.

Fig. 4, Pl. LIX, shows a slightly more advanced stage. In this case the upper sporogenous cell is smaller and the nucleus less conspicuous than usual. The cytoplasm of the young embryo-sac contains many vacuoles and the conspicuous nucleus occupies the centre of the cell. A slightly older stage is shown in Fig. 5. The sister cell of the young embryo-sac divides longitudinally, instead of transversely, as is the case in most Angiosperms. This has, however, been noted in a number of other forms, both Monocotyledons and Dicotyledons. ${ }^{1}$

The young embryo-sac increases rapidly in size and the nucleus divides, one of the daughter nuclei moving to the upper end of the sac, the other to the chalazal end. The two nuclei are quite similar in appearance (Fig. 7), and the cytoplasm still fills the whole cavity of the sac, although there are several large vacuoles. These vacuoles finally unite, and by the time the second mitosis is complete, a single large vacuole occupies the greater part of the sac, the cytoplasm being mainly confined to the ends, while there is only a thin layer lining the lateral walls (Figs. 8 and 9).

Up to this point Pandanus agrees exactly with the typical Angiosperms, but the later history of the embryo-sac is decidedly different. The two nuclei at the micropylar end of the sac remain for a long time undivided, and the next nuclear divisions are confined to the chalazal region. Stages with four, six, eight, and twelve nuclei at the chalazal end were met with, but in all of these there were but two micropylar nuclei. The cytoplasm in the basal region of the embryo-sac increases very much in amount as the nuclear divisions proceed. None of the nuclei at this stage were found in division, so that the sequence of nuclear divisions in

${ }^{1}$ Coulter, J. M., and Chamberlain, C. J. : Morphology of Angiosperms, 1903, pp. 75, 76. 
the chalazal region could not be determined. Several cases, one of which is shown in Fig. I 2, Pl. LIX, had six chalazal nuclei, but it could not be determined which of the four nuclei of the preceding stage gave rise to the two extra nuclei. There is some uncertainty as to the subsequent divisions by which the number of chalazal nuclei increase to eight, and finally to twelve. Usually, at least, there are finally twelve of these chalazal nuclei, although it is possible sometimes there may be only ten. There is some variation in the form of the lower end of the embryo-sac, which may be either somewhat pointed, or broad and rounded (see Figs. I4 and 15 ).

In the oldest stages that were secured in $P$. Artocarpus, the embryosac, which had increased materially in size, showed at the somewhat narrower micropylar end two nuclei, while at the chalazal end there were twelve large nuclei surrounded by a large mass of granular cytoplasm containing several conspicuous vacuoles (Figs. I4 and 15). A similar, but smaller, mass of cytoplasm surrounds the nuclei at the upper end of the sac, and the large central vacuole is bounded laterally by a rather thick layer of cytoplasm which, however, contains no nuclei. In most cases there was no apparent differentiation of the cytoplasm at the upper end of the sac, although in a few instances there was a slight indication of what looked like the separation of an egg-cell and synergid; but this was very vague.

Corresponding to the enlargement of the embryo-sac there is a marked increase in the size of the nuclei, which at the same time show a distinct reticulum, while in the younger sac the contents of the nucleus appear more uniform. The nucleolus is very conspicuous. In P. Artocarpus the increase in size is more marked in the chalazal nuclei than in the micropylar ones, which are noticeably smaller. In the most advanced stages found in $P$. Artocarpus the arrangement of the nucleus is very similar to that described by Johnson for Peperomia hispidula, ${ }^{1}$ except that there are fourteen instead of twelve chalazal nuclei in the latter, and these ultimately fuse into one enormous endosperm nucleus.

Owing to the similarity of the nuclei in the nucellus cells adjacent to the young embryo-sac, and those of the sac itself, the former may be mistaken sometimes for nuclei belonging to the embryo-sac, but in the later stages the greater size of the embryo-sac nuclei usually makes it easy to distinguish them. There is sometimes found a small cell (Fig. I3,y), apparently cut from the side of the embryo-sac, as occurs in the embryosac in Peperomia. The contents of these cells are densely granular like the cytoplasm of the embryo-sac, but the nuclei are small, and it is quite likely that these small cells really belong to the nucellus. The occasional occurrence of small nuclei apparently free in the cytoplasm of the embryo-

1 Johnson, D. S.: A New Type of Embryo-sac in Peperomia. Johns Hopkins University Circular, 1907, No. 3, pp. 19-21. 
sac, and differing in appearance from the other nuclei, suggests that perhaps the wall of an adjacent cell of the nucellus may have broken down and discharged the nucleus into the embryo-sac. These points, however, can only be settled when the history of the nuclear division is known.

All of the cells surrounding the embryo-sac differ more or less from the outer tissue of the nucellus, having more watery contents and sometimes rather larger nuclei; they are probably concerned to some extent with the nutrition of the embryo-sac, and sometimes this central mass of tissue suggests a mass of sporogenous cells; and it is not impossible that it really may represent a mass of sporogenous tissue of which one cell only is functional. In Fig. I8, Pl. LX, part of this tissue is shown with two conspicuous cells that very much resemble young embryo-sacs.

\section{The Embryo-sac of Pandanus odoratissimus.}

Pandanus odoratissimus was examined for comparison with P. Artocarpus, from which it was found to differ only in some minor particulars. This species has large fruits with the carpels united into groups, forming more or less complete compound pistils, but the union of the carpels is a very loose one. The upper part of the carpel soon becomes very hard and woody, but the base remains succulent for some time, and is easily sectioned. The inflorescences from which the preparations were made were about six centimetres in diameter, and it was supposed that fertilization had already taken place. It was therefore hoped that the later stages of the embryo-sac could be obtained, but on examination it was found that in spite of the large size of the carpels, which were nearly two centimetres in length, the ovules were little further advanced, and not noticeably larger than those in the apparently much younger and smaller flowers of P. Artocarpus. Pollen-spores were found on the stigma, and some of these had sent out their pollen-tubes. It was found, however, that the pollen-tubes had not yet reached the ovules. In $P$.odoratissimus the two micropylar nuclei are quite as large as those of the chalazal region, and the largest sacs found in this species were slightly larger than those of apparently the same age in P.Artocarpus. In some cases fourteen chalazal nuclei were counted, and occasionally a nucleus was found containing two nucleoli, looking in some cases as if there might have been fusion of two nuclei (see Fig. I6, Pl. LIX, and Fig. I7, Pl. LX).

\section{The Embryo-SAC of PANDANUs CORONATUS.}

The further study of the embryo-sac was confined to $P$. coronatus, as this was the only species secured in which the older embryo-sacs were found.

Fig. 2I, Pl. LX, shows an embryo-sac of this species corresponding to the oldest stages found in $P$. Artocarpus and $P$. odoratissimus, which it closely resembles, except for its decidedly larger size and somewhat more 
elongated form. A somewhat younger stage, with eight chalazal nuclei, is shown in Fig. 19, P1. LX.

Fig. 20 shows the base of an embryo-sac, differing somewhat from the usual type. It was apparently somewhat older than that figured in $2 \mathrm{I}$, being decidedly larger. There were two micropylar nuclei and ten large nuclei in the antipodal region. There were also present two or three small nuclei, but it was a question whether these properly belonged to the embryosac. The most remarkable feature of this embryo-sac was a very large free nucleus, closely resembling the primary endosperm nucleus formed in the older embryo-sac as the result of the fusion of the 'polar' nuclei. This nucleus (Fig. 20, b) was embedded in a mass of cytoplasm, and contained two very conspicuous nucleoli, which gave it very much the appearance of having resulted from the fusion of two of the twelve original antipodal nuclei. As a rule no such fusion nuclei were found until a much later stage of development.

In the next stages met with, the two micropylar nuclei had divided, so that there were four nuclei at the upper end of the sac, and the eight or twelve chalazal nuclei had increased in number to $32-6$. Although many preparations were made, none of them showed the division stages, and it is impossible to say whether the divisions of all the chalazal nuclei take place simultaneously, or whether the nuclei divide at the same time as the two micropylar nuclei.

In all these later stages the nuclei, which in the earlier condition were free, are separated by evident cell-walls, so that the base of the embryo-sac is occupied by a broad mass of antipodal cells very much like those that occur in Sparganinm after fertilization has taken place. ${ }^{1}$ There is, however, a marked difference to be noted. In Sparganium, at the time of fertilization, the embryo-sac has the usual form with three distinct antipodal cells. The very greatly increased number of antipodals found later results from a subsequent division of these three original antipodal cells. In Pandanus, however, up to the time that twelve or sometimes fourteen nuclei are present in the antipodal region, there is no trace of cell-division. The formation of this mass of antipodal cells in Pandanus resembles, therefore, very closely the formation of the endosperm after fertilization has taken place, and it is quite likely, although this is not easy to demonstrate, that more than one nucleus may sometimes be enclosed within the irregular cells composing the antipodal tissue..

In the micropylar region three of the four nuclei form a fairly typical egg apparatus (Figs. 22-4). Two of these, probably sister nuclei, give rise to the synergidae. The latter are separated by what seems to be a definite cell-wall, and are rounded off below, not presenting any peculiar character-

${ }^{1}$ See Campbell, Studies on the Flower and Embryo of Sparganium. Proc. Calif. Acad. of Sciences, 3rd Ser., Bot., vol. i, No. 9, 1899. 
istics different from those in the ordinary embryo-sac. The nuclei are about half the size of the primary micropylar nuclei, and the nucleolus is relatively larger and more conspicuous. The second micropylar nucleus presumably gives rise to the nucleus of the egg and a free nucleus, the upper polar nucleus $(p . n$.). This upper polar nucleus later moves towards the base of the sac and fuses with the lower polar nuclei to form the primary endosperm nucleus.

The cytoplasm of the egg-cell, which is not always very clearly differentiated, is less dense than that of the synergidae, and the nucleus, sometimes at least (see Fig. 22, c), is smaller, with a less conspicuous nucleolus.

The polar nucleus is at first in close contact with the egg, and in size and structure resembles its sister nucleus. As it moves towards the lower part of the embryo-sac it becomes very much larger, and at the time it fuses with the polar nuclei from the antipodal end it is impossible to distinguish it from them.

\section{The Antipodal Cells.}

The exact number of antipodal cells is not easy to determine, as sometimes the nuclei of the adjacent nuclear tissue become enlarged and strongly resemble the nuclei of the antipodal cells, with the outermost of which they may readily be confused. Moreover, there is undoubtedly much variation in the number of antipodal cells. In several cases thirty-two of these could be counted, while in others there were as many as sixty-four, and possibly the number may be even greater than this. In some of the preparations a number of the antipodal nuclei were in process of division, but no rule could be discovered governing the time of division. It is probable that the number of antipodal cells present at the time fertilization takes place depends, at least in part, upon the number of free nuclei in the chalazal region at the time cell-formation begins. So far as could be determined the number of these free nuclei may range from eight to fourteen, and it seems likely, although this could not be proved, that the next division in these nuclei is accompanied by the formation of cell-walls. The antipodal cells (Figs. 22-4) are of very irregular form and contain a good deal of granular cytoplasm which is more or less vacuolated, especially in the upper cells. These cells in the earlier stages are strongly turgescent, and the upper ones project into the cavity of the embryo-sac. In the later stages these upper cells appear more or less flattened or even collapsed (Fig. 25), but how far this is the normal appearance, and how far it is due to shrinkage in the preparation of material, is impossible to say.

From one or more of the upper cells the large nuclei are discharged into the cavity of the embryo-sac and constitute the lower polar nucleus 
(or nuclei). Figs. $23,24, p . n$. Pl. LX, show the antipodal cell containing the polar nucleus projecting into the cavity of the embryo-sac. The intermediate stages between this condition and that where the nuclei lie free within the cavity of the embryo-sac were not seen, but as there were in no cases any free basal nuclei in such stages as those shown in Figs. 23 and 24 , it seems pretty certain that the nuclei of these protruding antipodal cells are ultimately discharged into the cavity of the sac. The number of the basal polar nuclei varies from a single one to six or more. Most commonly there seem to be two or three, and the number is probably to some extent governed by the number of antipodal cells. There was no evidence that the increased number of polar nuclei was due to a division of the primary ones, although, of course, there is a possibility that such is the case.

At the time of fertilization the much enlarged embryo-sac shows a pretty well marked egg apparatus at the upper end, while at the chalazal end (Fig. 25) there may be seen a somewhat flattened mass of antipodal cells, in this case about sixty-four. The lowest antipodal cells are still turgescent and contain a good deal of granular cytoplasm, but the other ones appear collapsed and have very little contents, looking as if they were disintegrating. Some of these cells may perhaps be those from which the lower polar nuclei have been discharged.

Above the antipodal cells at the time of fertilization there may be seen a group of large nuclei closely crowded together, and beginning to fuse. As we have already seen, the number is usually from two to six, and it is quite impossible to tell which of these is the polar nucleus derived from the upper end of the sac, and which nuclei originated from the antipodal region. These nuclei subsequently fuse into a single large endosperm nucleus.

\section{Fertilization.}

The entrance of the pollen-tube into the embryo-sac was seen in a number of cases, but no satisfactory study of the details of fertilization could be made out. The pollen-tube is small, and could in some cases be seen forcing its way between the cells at the apex of the nucellus, but in no case were the nuclei satisfactorily shown, and although it is probable that there are, as usual, two generative nuclei, this cannot be positively asserted. Where the end of the tube could be seen within the sac, one of the synergidae, as usual, was destroyed. Presumably one of the generative nuclei is discharged into the sac, and small nuclei were sometimes seen in the neighbourhood of the recently fertilized egg which might possibly have been the generative nuclei, but it was quite as likely that these small nuclei were really derived from some of the nucellus cells which had been cut in sectioning the ovule. Nor were any satisfactory 
demonstrations made of the presence of a male generative nucleus within the egg, or its fusion with the egg nucleus.

The fusion of the polar nuclei takes place about the same time as the fertilization of the egg, but there is probably some variation in this respect. The fusing polar nuclei (Figs. 25, 26, P1. LX) are extremely conspicuous. Each one contains as a rule a single very large nucleolus and shows an evident reticulum, which does not stain at all strongly and is apparently rather deficient in chromatin. The nuclei become closely appressed and their cavities gradually fuse until there results a single very large nucleus, the primary endosperm nucleus, within which can still be clearly seen the separate nucleoli of the component nuclei. In the nucleus figured there were six large nucleoli, only two of which show in the figure. It is probable that the division of the primary endosperm nucleus follows quickly, as only one resting stage was found, while a number of cases were seen in which the nucleus was in process of division. In the resting nucleus which is figured the nuclear reticulum was more conspicuous than it is in the unfused polar nuclei, and there is much more chromatin, which shows in the form of distinct strongly staining granules.

In Figs. $30-2$ are shown the details from a very peculiar embryo-sac. At the upper end of the sac there was an imperfectly differentiated egg apparatus which showed four instead of three nuclei, and it was impossible to tell which of the four represented the egg. What looked like the end of the pollen-tube (p.t.) could be seen at the apex, but if this structure really was the pollen-tube, it had not yet destroyed either of the synergidae. Near the egg apparatus there was a single cell $(y)$ which looked very much like an egg-cell of the normal type. Near the middle of the sac there was a large mass of cytoplasm surrounding a group of about twelve large nuclei which were in process of fusion. Fig. 32 shows five of these. Near this group of nuclei there was a second cytoplasmic mass $(x)$ attached to the wall of the embryo-sac and containing what looked like two nuclei, but these were not very distinct. What would have been the further history of this abnormal embryo-sac is impossible to conjecture.

In other cases apparently otherwise normal it looked as if there were two primary endosperm nuclei. Thus in the embryo-sac from which the endosperm nucleus shown in Fig. 27 was taken, there was a second group of seven nearly completely fused nuclei.

The few preparations that were secured showing the division of the primary endosperm nucleus were all rather advanced metaphases of mitosis, no examples of prophases being found. Fig. 28, $a$, shows the nuclear spindle of the dividing primary endosperm nucleus. The chromosomes form an undivided equatorial plate. The number of the chromosomes, as might be expected from a nucleus made up of the fusion of several, is extremely large, and their small size and crowded position made it prac- 
tically impossible to determine their number. The two nuclei resulting from this first division were not seen, and the next stage met with showed four large endosperm nuclei, one of which is shown in section in Fig. 29, $a$, P1. LX. These nuclei were of about the same size as the primary endosperm nucleus and showed much the same structure, containing several large nucleoli and a conspicuous reticulum.

With the successive divisions of the endosperm nuclei there is a marked reduction in their size, and this reduction in size is accompanied by a reduced number of chromosomes, as may be seen by comparing Fig. 28, $b$, with Fig. 28, $a$. The former nuclear spindle was from a nucleus of about the same size as that shown in Fig. 29. The free endosperm nuclei are evenly distributed through the cytoplasm lining the embryo-sac, and this cytoplasmic layer increases a good deal in thickness before the formation of cell-walls in the endosperm begins. At the time the first walls are formed in the endosperm, the nuclei are still further diminished in size (Fig. 29, a), and presumably the number of chromosomes is correspondingly less than in the earlier and larger free endosperm nuclei.

\section{The EMbRYo.}

The embryo in Pandanus remains very small even in the ripe seed, and in the largest ovules that were sectioned, which had attained a length of more than a centimetre, the embryo was still quite undifferentiated. The early divisions take place slowly and the embryo remains unicellular for a long time after fertilization (Fig. 33). The first division, in some cases at least, is transverse and separates a short suspensor cell from a larger terminal cell (Fig. 34), but the number of young embryos examined was too small to make it certain whether the first divisions are always the same. Text-fig. 2, A, B, shows a four-celled embryo with probably a one-celled suspensor $(s)$, although it is possible that this basal cell may belong to the nucellus.

The oldest embryos seen are shown in Text-fig. 2, C, D. These were nearly oval bodies without any definite suspensor. They showed no signs of the permanent organs of the young plant, and it is therefore impossible to say what is the method of origin of the stem apex and the other organs of the seedling. In order to follow out the further history of the embryo it would probably be necessary. to germinate the seeds, as even in the ripe seed the embryo is quite rudimentary.

In the development of the embryo Pandanus differs very much from Sparganium, where the embryo in the ripe seed is very large and all the organs perfectly developed. The earlier stages in Pandamus are not very unlike the corresponding ones in Sparganium (compare for example Fig. 37 of my paper on Sparganium with Text-fig. 2, C). 
The development of the endosperm begins at the apex of the embryosac, and the first division walls are formed while the embryo is still very small (Text-fig. 2, A, B). The development of the endosperm tissue does not seem to differ in any way from the ordinary method, and no particular study was made of this point. Between the nuclei there arise simultaneously the division walls, which form an irregular tissue increasing by division and growth until the whole embryo-sac is filled with a continuous mass of endosperm cells.

The hard testa of the seed is derived mainly from the outer integument, the inner integument being almost obliterated during the ripening of the seed.

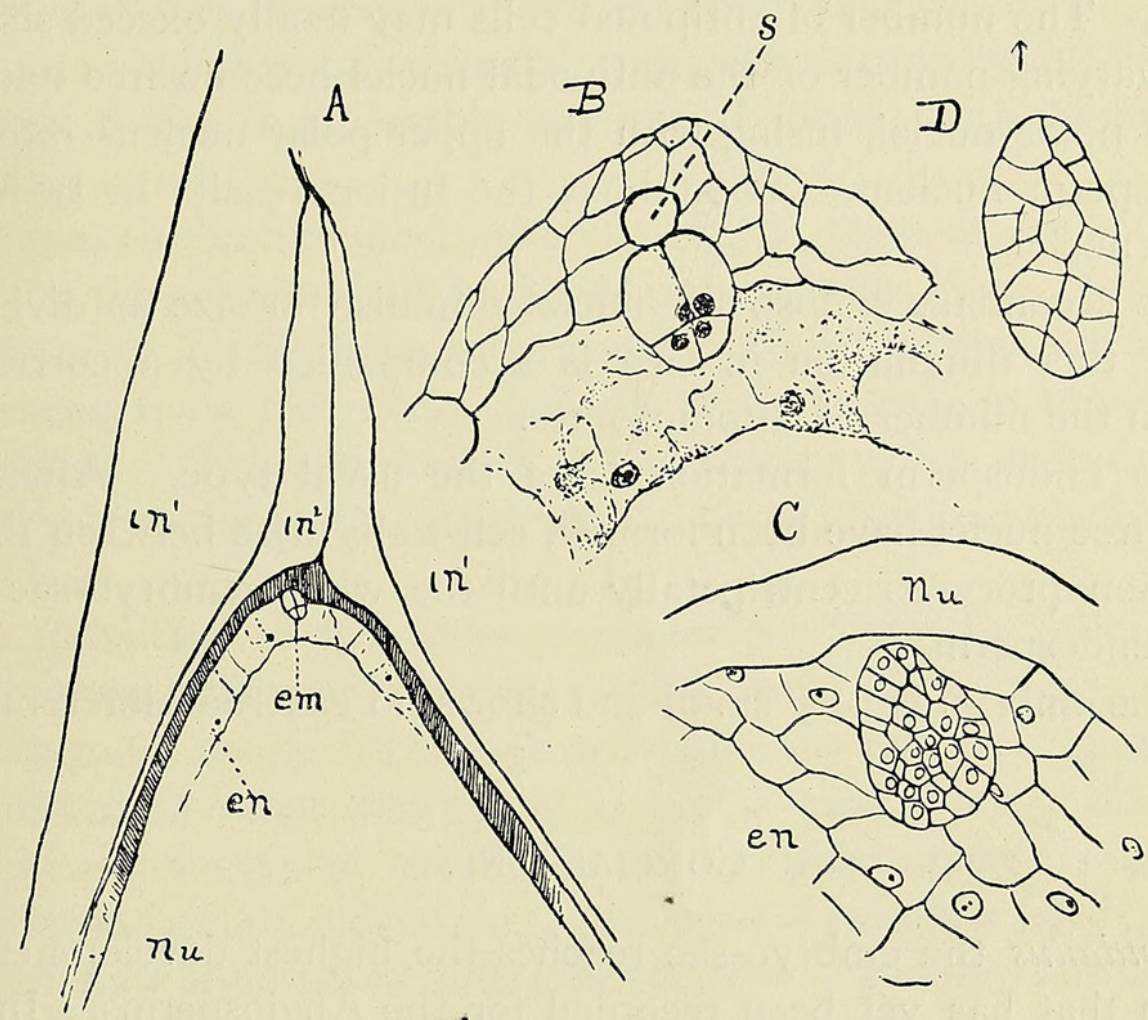

TeXt-FIG. 2. A. Upper part of the ovule and embryo-sac of Pandanus coronatus, Martelli, showing a young embryo embedded in the endosperm, en. The shaded portion represents the tissue of the nucellus. $x$ about $4^{0}$. B. The embryo shown in A, more highly magnified. The round cell at the base of the four-celled embryo may be the suspensor, but this is not certain. c. An older embryo, embedded in the endosperm, en. $\times 225$. D. A still older embryo. $\times 225$. The arrow points towards the micropyle.

\section{SUMMARY.}

I. The primary sporogenous cell is separated from the epidermis of the nucellus by several layers of parietal cells presumably derived from the division of a single primary tapetal cell. The cells of the nucellus adjacent to the embryo-sac sometimes show an appearance suggesting that they may be abortive sporogenous cells.

2. The sporogenous cell divides into a large lower cell and a smaller 
upper one, the latter dividing again by an anticlinal wall. The lower cell is the young embryo-sac.

3. The early divisions of the embryo-sac follow the usual course up to the stage with four nuclei, two being at each pole of the embryo-sac.

4. The next divisions are confined to the antipodal region where the two original nuclei, by subsequent divisions, give rise to a group of large free nuclei, usually twelve in number.

5. The two micropylar nuclei divide once, and there is formed a typical egg apparatus and an upper polar nucleus.

6. The antipodal nuclei divide further, the later divisions being accompanied by the formation of cell-walls much as in the formation of the endosperm. The number of antipodal cells may finally exceed sixty-four.

7. A varying number of the antipodal nuclei become free and assume the rôle of polar nuclei, fusing with the upper polar nucleus into a single large endosperm nucleus. Sometimes the fusion results in two primary endosperm nuclei.

8. The secondary endosperm nuclei diminish in size as division proceeds, and this diminution in size is accompanied by a corresponding reduction in the number of chromosomes.

9. The endosperm formation is of the usual type. After a large number of free nuclei have been formed, cell-walls arise between them, and cell-formation proceeds centripetally until the whole embryo-sac is filled with solid endosperm.

Io. The embryo is very small and shows no external differentiation.

\section{CONCLUSiOnS.}

In Pandamus the embryo-sac reaches the highest development before fertilization that has yet been recorded for the Angiosperms. Instead of the eight nuclei of the ordinary embryo-sac there are at least thirty-six, and sometimes twice that number, at the time fertilization occurs.

The early history of the embryo-sac follows closely the usual course up to the time that four nuclei have been formed, and then a difference is to be noted. The condition with two micropylar nuclei and eight to fourteen free nuclei at the base of the embryo-sac may be compared to that described by Johnson for Peperomia hispidula, ${ }^{1}$ where there is a similar arrangement of the nuclei. The eight-nucleate stage found in Gunnera macrophylla ${ }^{2}$ also resembles this stage of Pandanus, but the final nuclear division in Gunnera, resulting in sixteen nuclei, is accompanied by

1 Johnson, D. S. : A New Type of Embryo-sac in Peperomia. Johns Hopkins "University Circular, 1907, No. 3, pp. I9-2 I.

${ }^{2}$ Ernst, A.: Zur Phylogenie des Embryosackes der Angiospermen. Ber. der deutsch. bot. Gesellsch., xxvi, 1908, pp. 419-38. 
the formation of division cells, while in Pandanus cell-formation does not take place until a later period.

It is in the subsequent history of the embryo-sac that Pandamus shows the greatest departure from the usual angiospermous type. The extraordinary development of the antipodal cells at the time of fertilization exceeds that found in any other form. In Peperomia pellucida and in Gunnera, where there are sixteen nuclei in the adult embryo-sac, there are six antipodal cells, and in some of the Grasses ${ }^{1}$ there may be as many as thirty-six, and the number is often increased in many Compositae. But in all of these except Peperomia and Gunnera there is first developed a typical embryo-sac with three antipodal nuclei. These later undergo secondary divisions resulting in the increased number of antipodal cells. The increased number of antipodal cells, subsequent to fertilization, has been observed in a considerable number of forms, both Monocotyledons and Dicotyledons. ${ }^{2}$

In Pandamus, unlike these other forms, the mass of antipodal tissue is preceded by the formation of a considerable number of free nuclei, and the solid mass of antipodal tissue is formed by the subsequent division by cellwalls between these free nuclei exactly as is the case in the formation of the endosperm. This emphasizes the homology which undoubtedly exists between the two types of gametophytic tissue developed before and after fertilization.

The formation of the endosperm nucleus from the fusion of several nuclei is not peculiar to Pandanus. The same thing occurs regularly in Peperomia and Gunneva, and there are numerous other instances that have been observed in other plants. It is pretty clear from a study of these forms that the theory of the fusion of the polar nuclei being a sort of sexual process is quite untenable. Just what it means is hard to say.

While there are marked differences between Pandanus and Sparganium, especially in the condition of the embryo-sac at the time of fertilization, and the much better developed embryo in Sparganium, still the general morphology, and particularly the great development of antipodal tissue which finally is formed in Sparganium, confirm the view that the Pandanaceae and Sparganiaceae do really belong near together in the system.

There seems no valid reason for supposing that the condition of the embryo-sac found in Pandanus is not really primitive. The genus on other grounds has been placed near the bottom of the series of Monocotyledons, and the structure of the embryo-sac certainly confirms this view. The arguments that have been brought against assuming that the

1 Cannon, W. A. : A Morphological Study of the Flower and Embryo of the Wild Oat, Avena fatua, L. Proc. Calif. Acad., 3rd Ser., Bot., vol. i, 1900, pp. 329-64.

${ }^{2}$ For a full account of the occurrence of more than three antipodal cells, see Coulter and Chamberlain, Morphology of Angiosperms, 1903, pp. 97-102. 
sixteen-nucleate embryo-sac of Peperomia is primitive (which we do not think are very convincing) ${ }^{1}$ cannot be applied to Pandamus. Since there are three megaspores produced in Pandanus, the embryo-sac can at most represent two of these, and as it may contain more than sixty-four nuclei, to speak of a reduction is out of the question. We entirely agree with Ernst ${ }^{2}$ in believing that the time has come to recognize that the embryo-sacs with an increased number of nuclei are not abnormalities, but are rather older types of embryo-sacs which have survived. It is more than likely that the number of these types will be increased as a further investigation of the lower members of both the monocotyledonous and dicotyledonous series is made.

Whether the indefinite type of structure shown by Peperomia, with its poorly organized egg apparatus, is an older type than that of Pandamus or Gunnera, where a typical egg apparatus is present, is not easy to answer, although we are inclined to believe that it is.

There is little question that the type of Pandanus is more primitive than that of Sparganium, where the large development of antipodal tissue is secondary. The latter may very well be derived from the former, but the reverse is hardly conceivable.

\section{EXPLANATION OF PLATES LIX AND LX.}

Illustrating Prof. Campbell's paper on the Embryo-sac of Pandanus.

PLATE LIX.

Fig. I. $a$, two young pistillate flowers of Pandanus affinis, Kurz. $\times 3 . \quad b$, a somewhat older flower of $P$. Artocarpus, Griff. $\times 3$.

Fig. 2. Two pollen-spores of Pandanus sp., showing the small prothallial (?) cell $\left(m_{1}\right) . \quad \times 600$.

Fig. 3. Median section of the nucellus of a young ovule of $P$. affinis. The sporogenous cell is still undivided. $\times 600$.

Fig. 4. The young embryo-sac of $P$. Artocarpus, with the sister cell, $x . \quad \times 600$.

Fig. 5. The upper part of the young nucellus of P. Artocarpus, showing the embryo-sac and the two cells, $x$, derived from its sister cell : $t$, the tapetal or parietal cells. $\times 600$.

Fig. 6. The young embryo-sac of $P$. Artocarpus, with a single row of tapetal cells above it. The cell $x$ is probably a sister cell of the embryo-sac. $\times 600$.

Fig. 7. Young embryo-sac of $P$. Artocarpus, in which the primary nucleus has divided.

Fig. 8. A somewhat older embryo-sac of the same species; a large vacuole has developed in the embryo-sac. $\times 600$.

Figs. 9-II. Young embryo-sac of $P$. Artocarpus with four nuclei. In Figs. 9 and Io, $a$ is the micropylar region; $b$, the chalazal. $\times 600$.

Fig. I 2. $a$, nearly median section of an embryo-sac of $P$. Artocarpus with six chalazal nuclei, of which three show in this section; one of the two micropylar nuclei can be seen; $b$, another section of the same, showing the second micropylar nucleus and the two sister cells of the embryo-sac.

1 See Bulletin of the Torrey Botanical Club, xxxvi, 1909, pp. 205-20.

2 Ernst, A.: Zur Phylogenie des Embryosackes der Angiospermen. Ber. der deutsch. bot. Gesellsch., xxvi, 1908, pp. 419-38. 
Fig. I3. Two sections of an embryo-sac of $P$. Artocarpus with twelve (?) chalazal nuclei ; the small cell, $y$, probably belongs to the nucellus. $\times 300$.

Fig. I4. Embryo-sac of $P$. Artocarpus, with six (?) chalazal nuclei ; $b$, the micropylar part of the same, showing the two sister cells $(x)$ of the embryo-sac.

Fig. I5. Three sections of an embryo-sac of $P$. Artocarpus with twelve chalazal nuclei. The two micropylar nuclei are shown in $a$ and $b . \quad \times 300$.

Fig. 16. Two sections of an embryo-sac of $P$. odoratissimus, L. f., with fourteen chalazal nuclei; two of the nuclei may have belonged to the adjoining nucellar tissue. $\times 300$.

\section{PLATE LX.}

\section{All figures except $\mathbf{1} 7$ and 18 refer to Pandanus coronatus.}

Fig. I7. a, cross-section through the apex of the embryo-sac of Pandanus odoratissimus, showing the two micropylar nuclei; $b$, section through the base of the embryo-sac, showing six of the fourteen chalazal nuclei. $\times 300$.

Fig. I8. Tissue of the nucellus near the embryo-sac, showing cells that resemble young secondary sacs. $\times 600$.

Fig. 19. Longitudinal section of an embryo-sac, showing one of the two micropylar nuclei and three of the eight chalazal nuclei. $\times 300$.

Fig. 20. $a$, base of an embryo-sac with ten nuclei in addition to the large nucleus shown at $b$. $\times 300$.

Fig. 2I. Embryo-sac with two micropylar and twelve chalazal nuclei. $\times 300$.

Fig. 22. $a$, embryo-sac, in which there were thirty-two antipodal cells and four micropylar nuclei, forming an egg apparatus and polar nucleus, $p . n . ; b, c$, two sections of the egg apparatus from the same sac; $a$, egg; sy, synergidae. $\times 300$.

Fig. 23. $a, b$, sections of the egg apparatus from a nearly mature embryo-sac; $c$, the basal part of the same sac, showing the lower polar nucleus, $p . n$., just separating from the mass of antipodal cells. $\times 300$.

Fig. 24. $a$, egg apparatus and polar nucleus, $p . n$., from a nearly mature embryo-sac; $b$, basal region of the same. There were abont thirty-six antipodals. A single polar nuclens, $p . n$., was separating from the mass of antipodal tissue. $\times 300$.

Fig. 25. Basal region of an embryo-sac, about the time of fertilization. There were about sixty-four antipodal cells, and three polar nuclei, the latter in process of fusion. $\quad \times 400$.

Fig. 26. Four fusing polar nuclei from a sac that has just been fertilized. $\times 400$.

Fig. 27. Endosperm nucleus formed by the complete fusion of probably six polar nuclei. A second group of fusing nuclei, seven in number, was present in this same sac. $\times 600$.

Fig. 28. $a$, the primary endosperm nucleus in process of division. $\times 600 . b$, dividing endosperm nucleus of about the same age as that shown in Fig. 29, $b$.

Fig. 29. $a$, one of four nuclei, resulting from the division of the primary endosperm nucleus; $b, c$, endosperm nuclei from a more advanced embryo-sac, but before the development of any cellwalls in the endosperm; $d$, nucleus at the time of the formation of the first cell-walls in the endosperm. $\times 600$.

Fig. 30. $a$, an embryo-sac in which there was a group of twelve fusion nuclei, e. n., and a second double nucleus, $x$, as well as a cell $(y)$ resembling an egg-cell, in addition to an egg apparatus of four cells. $\times 95 . \quad b, c, x$ and $y$ of $a$-more enlarged.

Fig. 3r. Two sections of the egg apparatus of the embryo-sac shown in Fig. 3 o. There were four nuclei, but the synergidae and egg were not clearly defined. A structure $(p . t$.$) resembling$ a pollen-tube could also be seen, but the nature of this was doubtful. $\times 600$.

Fig. 32. Five of the twelve polar nuclei of the sac shown in Fig. $30 . \quad \times 600$.

Fig. 33. $a$, upper part of the nucellus and embryo-sac, showing a one-celled embryo: sy, remains of a synergid. $\times 235 . \quad b$, the embryo. $\times 500$.

Fig. 34. Two sections of a two-celled embryo. $\times 500.5 y$, remains of the synergidae. $\times 500$. 
Annals of Botany
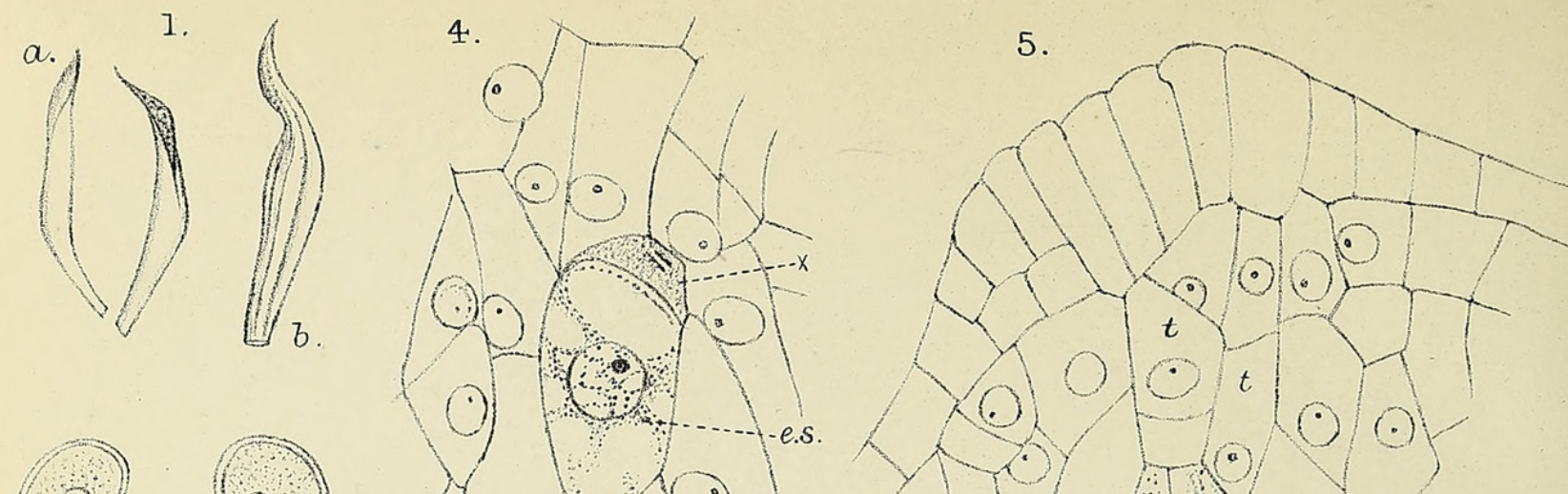

(2) 2. (ए)
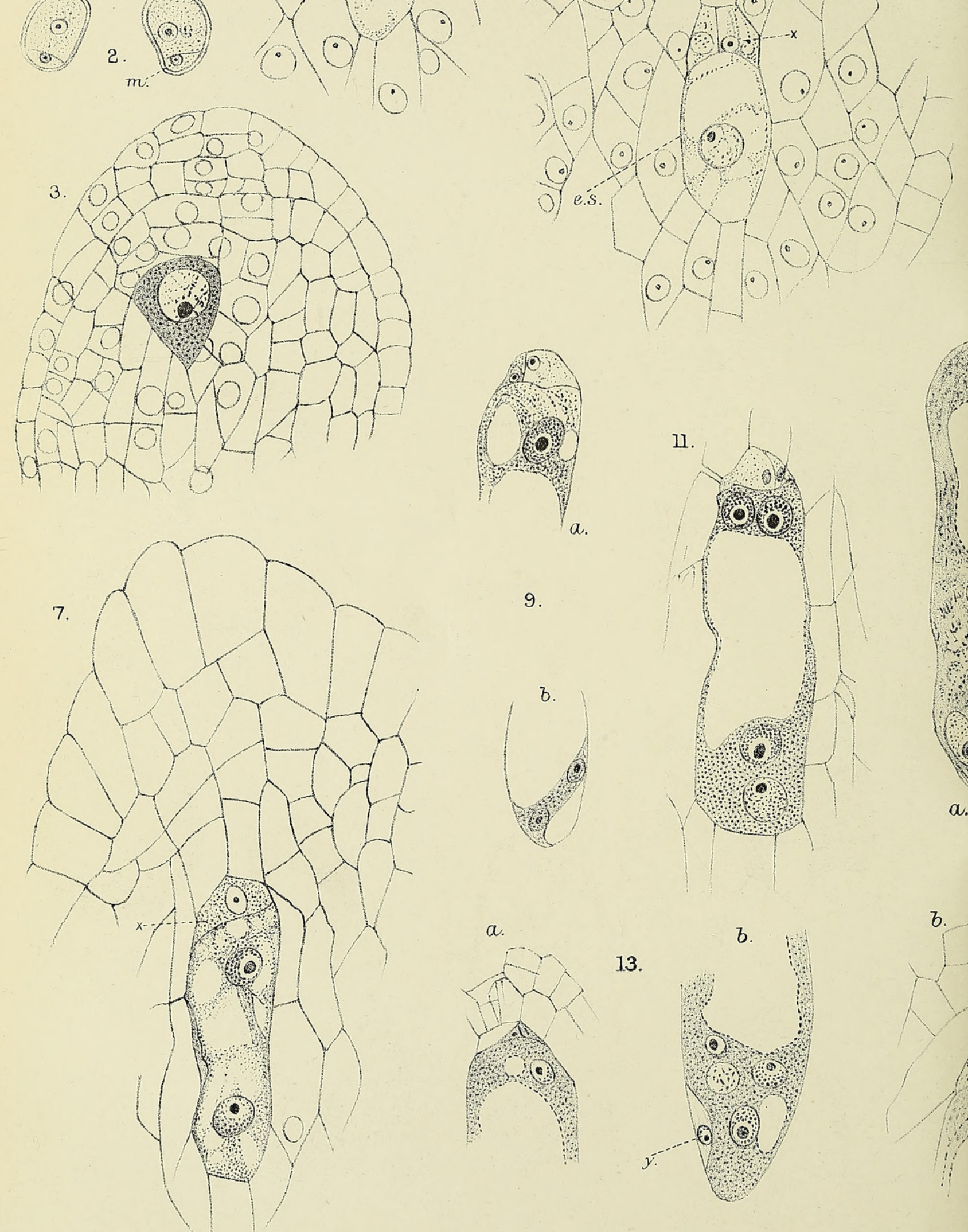
Annals of Botany

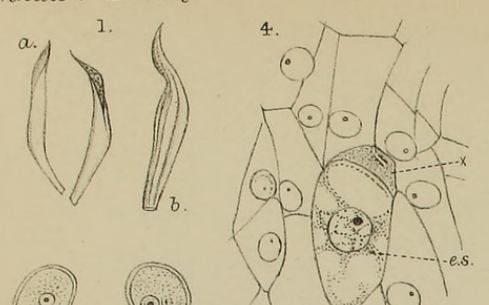

0.9
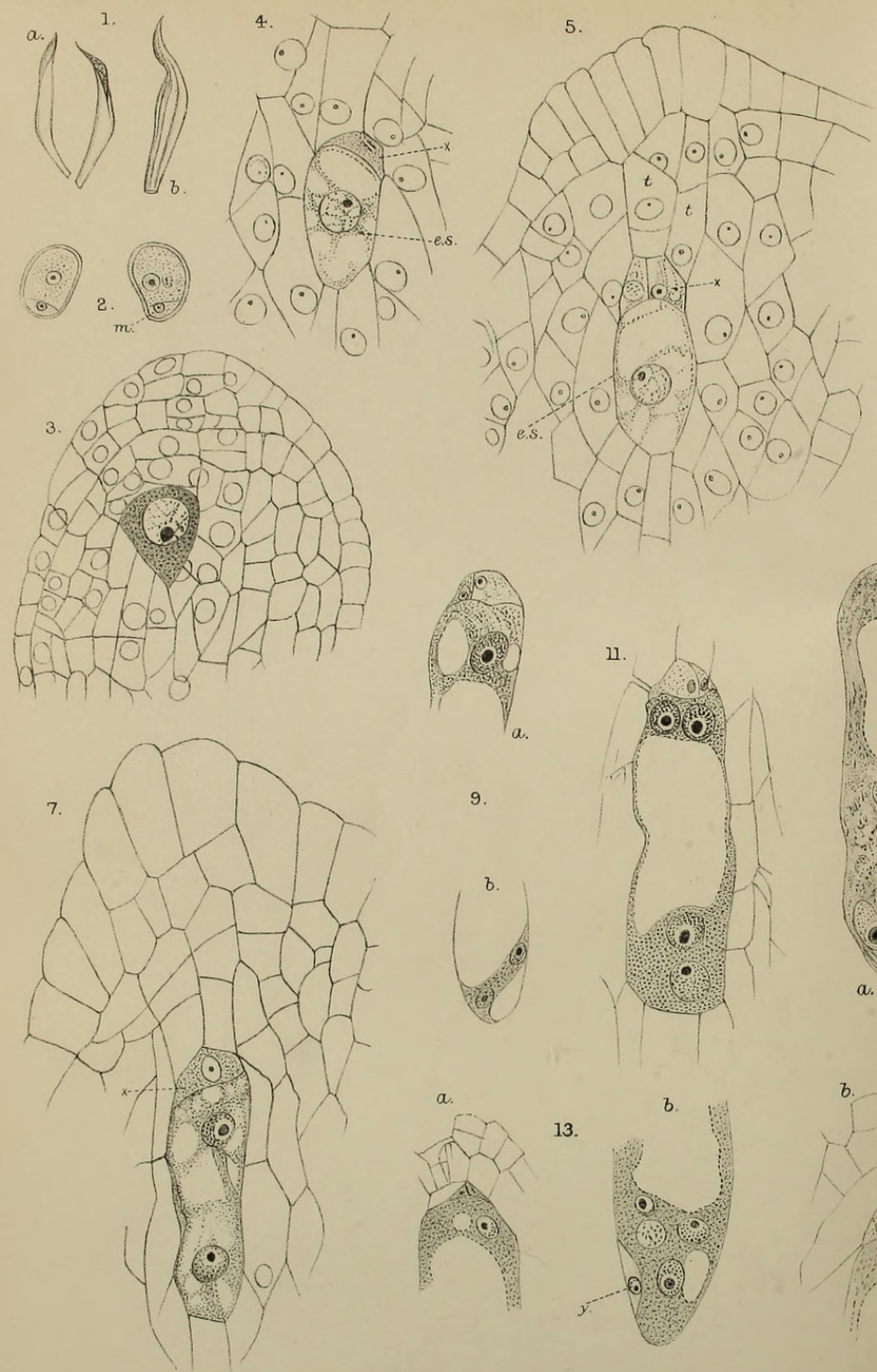

30000 :
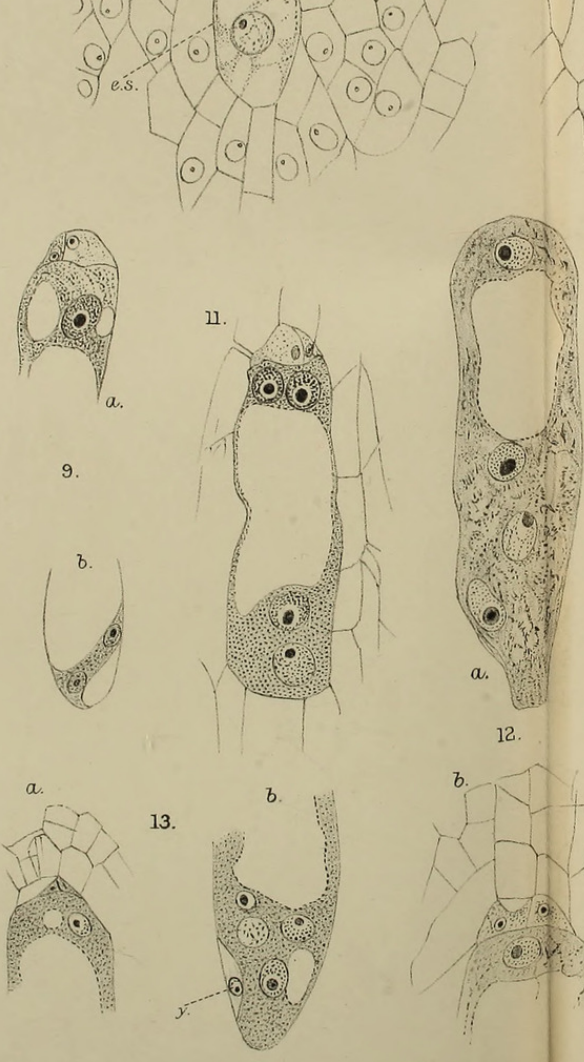
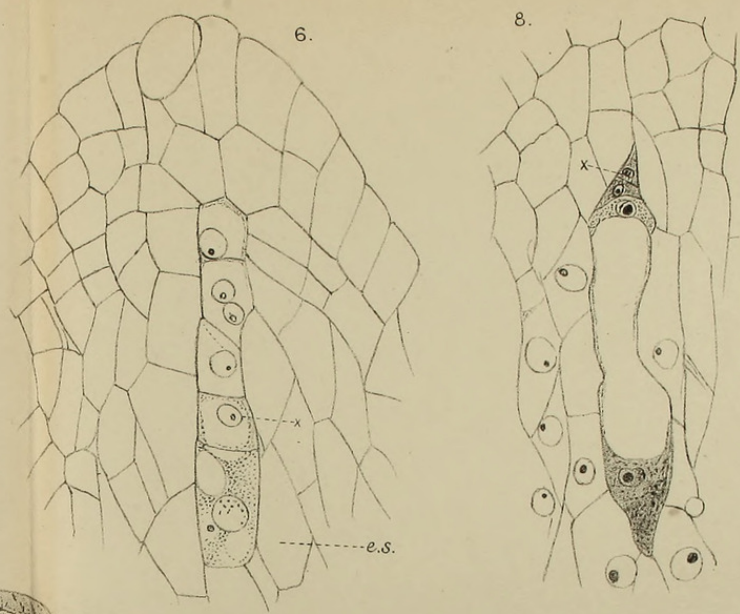

Vol. XXV. Pl.LLX:
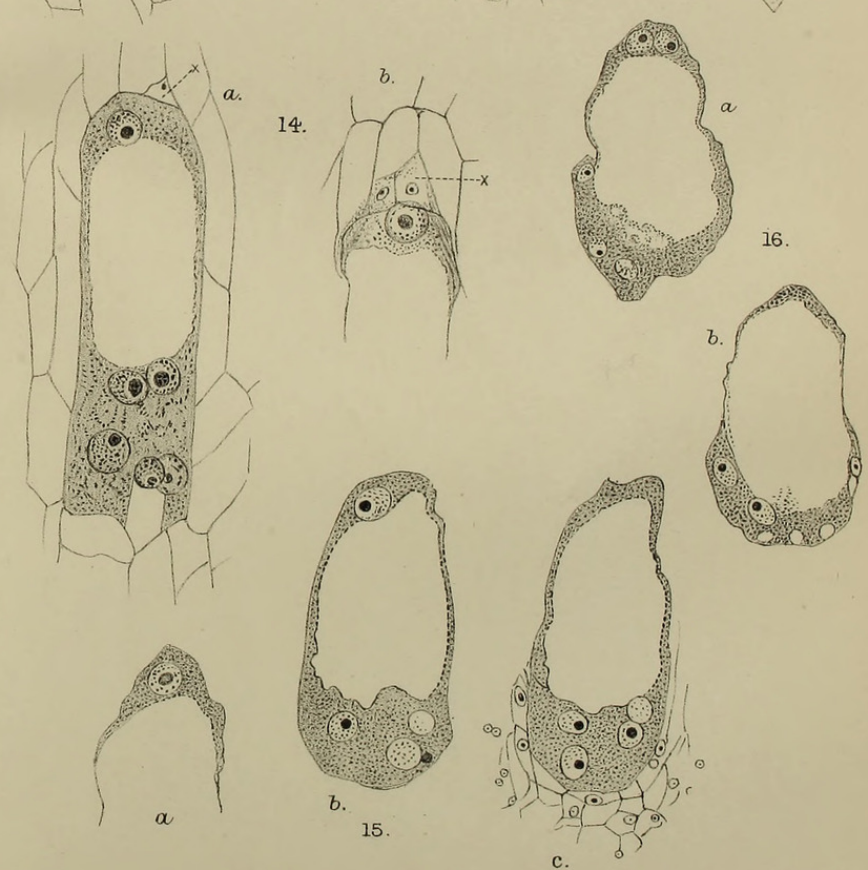


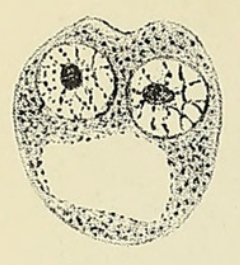

a.
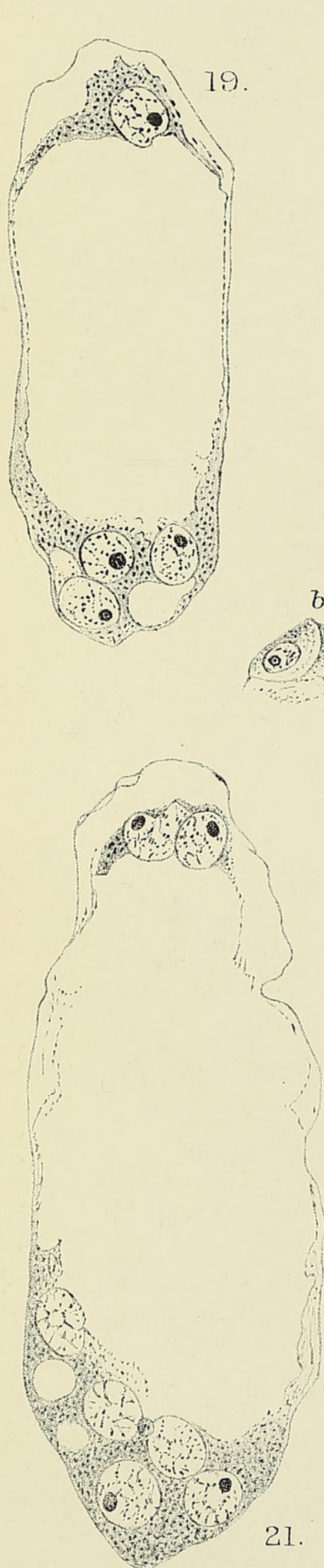

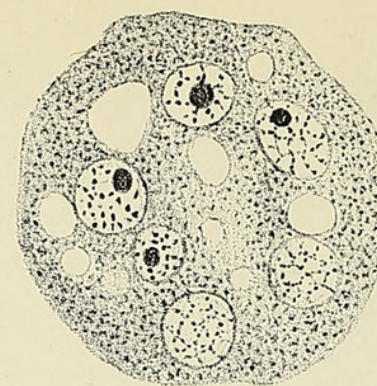

b.

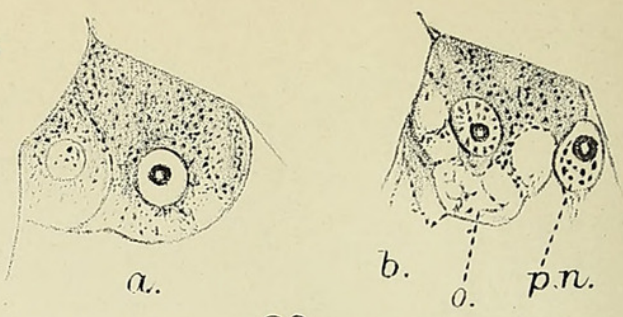

23.

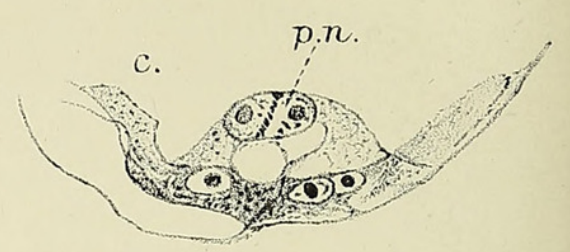

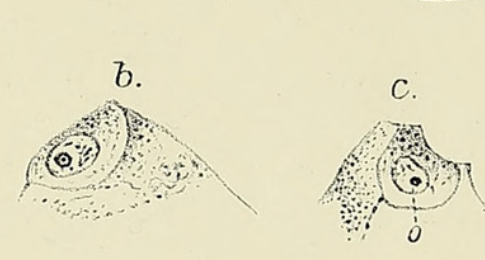
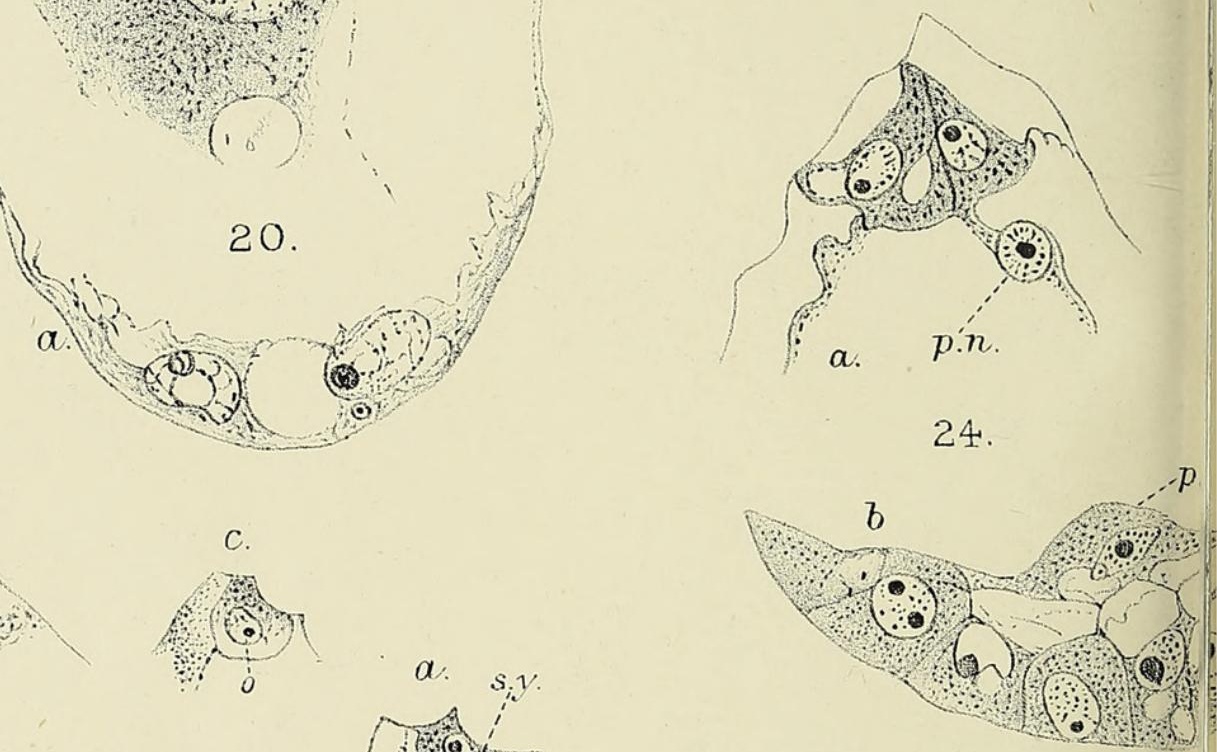

25.

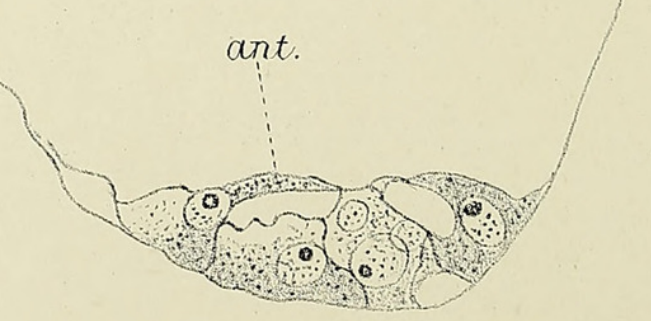

b.

29. 

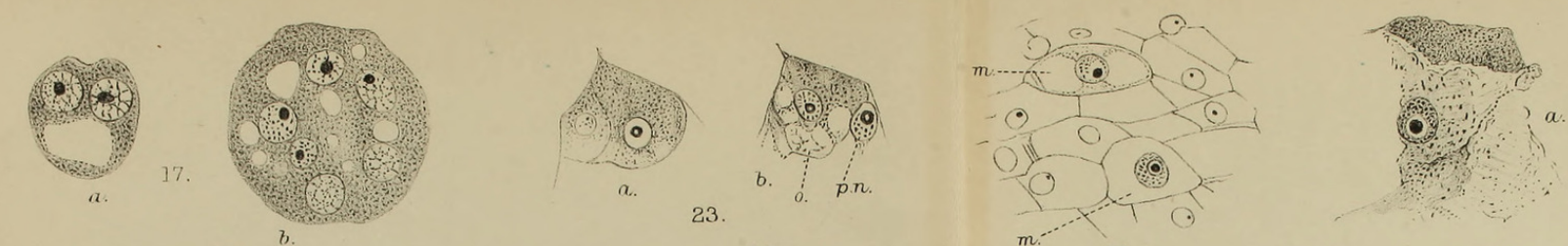

31.
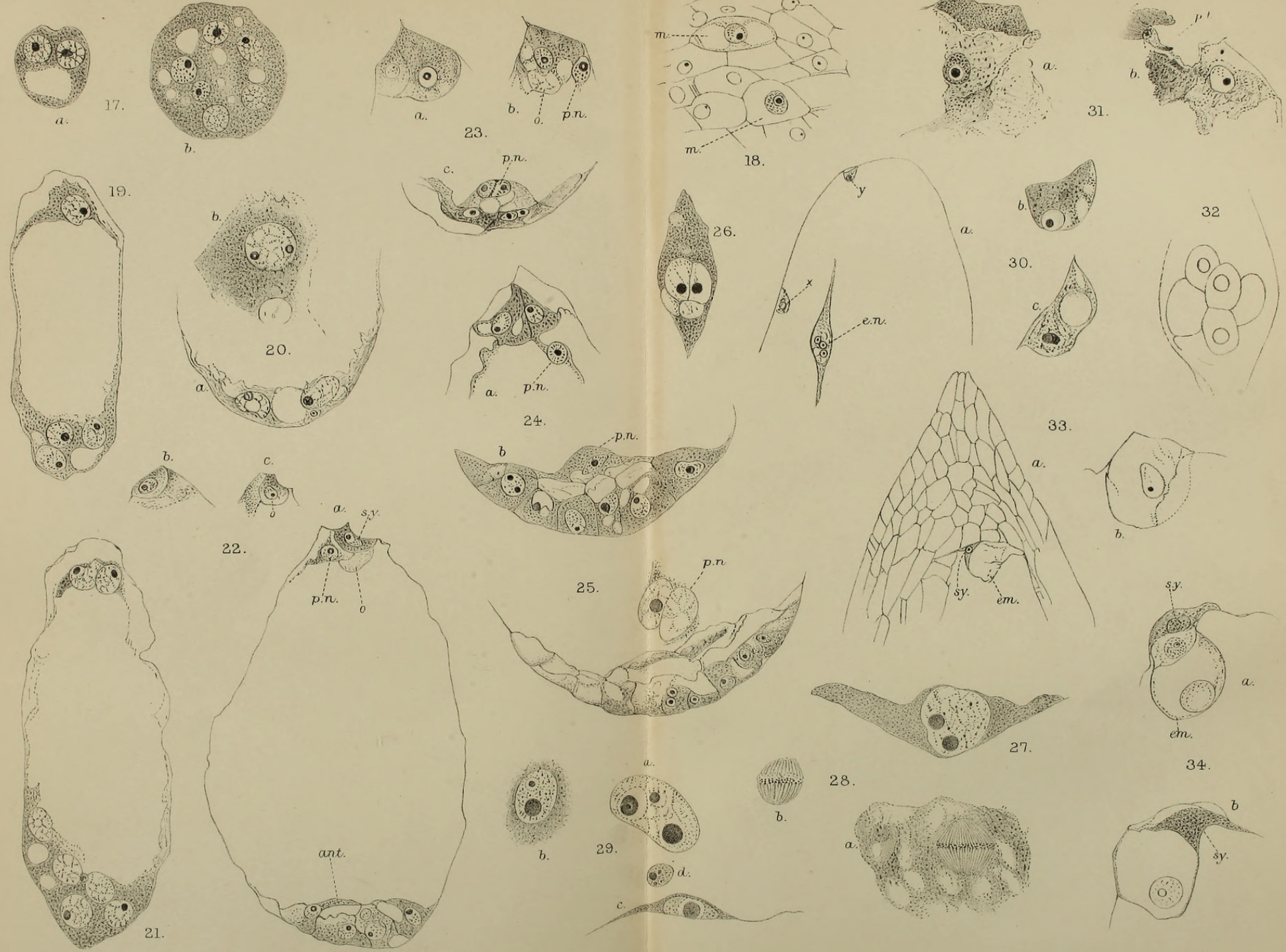

28.

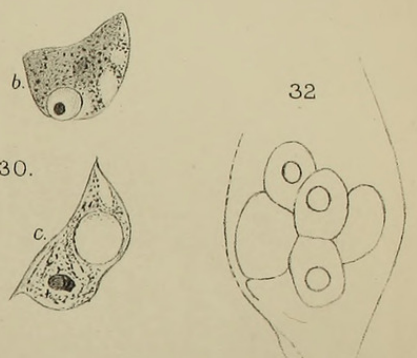




\section{$2 \mathrm{BHL}$ Biodiversity Heritage Library}

Campbell, Douglas Houghton. 1911. "The embryo-sac of Pandanus." Annals of botany 25, 773-789. https://doi.org/10.1093/oxfordjournals.aob.a089353.

View This Item Online: https://www.biodiversitylibrary.org/item/239487

DOI: https://doi.org/10.1093/oxfordjournals.aob.a089353

Permalink: https://www.biodiversitylibrary.org/partpdf/319861

\section{Holding Institution}

Smithsonian Libraries

\section{Sponsored by}

Biodiversity Heritage Library

\section{Copyright \& Reuse}

Copyright Status: Not in copyright. The BHL knows of no copyright restrictions on this item.

This document was created from content at the Biodiversity Heritage Library, the world's largest open access digital library for biodiversity literature and archives. Visit BHL at https://www.biodiversitylibrary.org. 